\title{
Contracts Adjustment under Bilateral Information Updating in a Supply Chain
}

\author{
Xinhui Wang, ${ }^{1}$ Yingsheng Su $\mathbb{D}^{2},{ }^{2}$ Zihan Zhou, ${ }^{3}$ and Yiling Fang ${ }^{4}$ \\ ${ }^{1}$ School of Computer Science and Technology, Southwest Minzu University, Chengdu 610041, China \\ ${ }^{2}$ School of Statistics, Southwestern University of Finance and Economics, Chengdu 610074, China \\ ${ }^{3}$ School of Business, Singapore University of Social Sciences, Singapore 599494 \\ ${ }^{4}$ Business School, Sichuan University, Chengdu 610064, China \\ Correspondence should be addressed to Yingsheng Su; suys@swufe.edu.cn
}

Received 22 July 2019; Revised 18 December 2019; Accepted 23 January 2020; Published 25 February 2020

Academic Editor: Dehua Shen

Copyright $\odot 2020$ Xinhui Wang et al. This is an open access article distributed under the Creative Commons Attribution License, which permits unrestricted use, distribution, and reproduction in any medium, provided the original work is properly cited.

\begin{abstract}
This paper investigates contracts adjustment between one manufacturer and one retailer under bilateral information updating. The manufacturer incurs uncertain production cost and the retailer faces uncertain demand, but they can acquire independent signals to update production cost and demand, respectively. They commit an initial agreement on an initial wholesale price, minimum order quantity, and information sharing as well as the transfer payment and decisions adjustment when information is updated. We find that due to the joint impact of production cost variation and market variation, the manufacturer may not decrease (increase) her wholesale price when the updated production cost is lower (higher) than expected. The retailer places an additional order even if the wholesale price rises when the market outlook is good, but places an order with the minimum order quantity even if the wholesale price falls when the market outlook is bad. Secondly, for a certain level of information accuracy of the production cost and market demand, the retailer is always better off with information updating, but the manufacturer may be worse off with information updating when facing a bad market outlook. Thirdly, when information accuracy of the production cost and market demand varies, the manufacturer only benefits from a high accuracy of production cost. Profits of the retailer and the supply chain are increasing (decreasing) with accuracy of production cost if the updated production cost is larger (smaller) than expected.
\end{abstract}

\section{Introduction}

Information largely affects the performance of supply chain firms. This is because better information contributes to better decisions, fewer mistakes, lower costs, and better products. Therefore, supply chain firms prefer to make their decisions until information is updated. For instance, a retailer determines his order until an update on demand [1] or determines his order and retail price until an update on supply yield [2]. However, some firms make their decisions before accurate information becomes known. For example, senior managers at Ericsson, a large telecommunications company, state that they often negotiate component prices 9 to 12 months before new products are put into production [3]. In the fashion industry, retailers place their orders many months before the selling season [2]. In a more general situation, when supply information and demand information are both uncertain, both retailers and manufacturers have incentives to adjust their decisions based on bilateral information updating to improve their performances. For example, in the flu vaccine industry, supply is uncertain due to the biological nature of vaccine production. Demand is also uncertain because it is mainly determined by the prevalence and severity of unpredictable flu activity [4]. Moreover, production lead time is as long as six to eight months. Under this scenario, a common practice is to place advance orders long before the actual flu season. When more information is available, the order quantity and wholesale price will be adjusted [5]. While most existing research focuses on supply information updating or demand 
information updating, this work considers a more general interaction between the supply chain parties under bilateral information updating. We have the following research questions. With supply information updating and demand information updating, how should supply chain firms make their optimal decisions under bilateral information updating? Who will benefit more from the updated information? How will information updating and information accuracy affect the supply chain?

To answer the abovementioned questions, we consider a supply chain consisting of one manufacturer and one retailer. We formulate the interactions between the manufacturer and the retailer as a Stackelberg game in which the manufacturer is a leader and the retailer is a follower. We consider contracts that agree on decisions adjustment and information sharing after bilateral information updating. Specifically, the manufacturer initiates a wholesale price and the retailer commits a minimum order quantity based on the pre-expectations of the production cost and market demand. After sharing updated information, the supply chain parties adjust their decisions. The transfer payment between the manufacturer and the retailer is designed in a way that links the initial wholesale price and the committed minimum order quantity to the updated wholesale price and the updated order quantity. We focus on how production cost variation, demand variation, and information accuracy affect the two parties' decisions. We further analyze the value of information updating and examine the impact of information accuracy on profits and the value of information updating. Some key conclusions and managerial insights are as follows.

First, the market outlook plays a moderating role in the relationship between the wholesale price and the production cost; it also affects the retailer's optimal order quantity. Specifically, the manufacturer may not reduce (raise) her wholesale price when the updated production cost is lower (higher) than expected. When the market outlook is good, even if the wholesale price rises, the retailer still places an additional order. When the market outlook is bad, reducing the wholesale price does not necessarily attract the retailer to place more orders. Second, the retailer and the supply chain are better off with information updating, but the manufacturer may not always benefit from information updating. For the manufacturer, when she gives a high wholesale price, she benefits from bilateral information updating; when she gives a low wholesale price, she may not benefit from information updating. This is because the value of information updating for the manufacturer depends on market outlook and production cost variation. When the market outlook is bad and the manufacturer's optimal wholesale price is lower than the one in the initial agreement, there exists an interval of production cost, in which, the order quantity first decreases and then remains the initial commitment order and the wholesale price increases. Thus, the joint effects of the wholesale price variation and order variation offset the positive effect of information updating on the manufacturer. Third, profits of the manufacturer, the retailer, and the supply chain are dependent on information accuracy of production cost and market demand, the production cost variation, and market outlook. Facing good market outlook and lower production cost, high information accuracy of production cost or high information accuracy of market demand is beneficial to the manufacturer, the retailer, and the supply chain. On the contrary, when facing bad market outlook and high production cost, high information accuracy of production cost or high information accuracy of market demand is harmful to the manufacturer, retailer, and supply chain.

The rest of this paper is organized as follows. Section 2 reviews the relevant literature, and Section 3 states model assumptions and the initial decisions for the manufacturer and the retailer. Section 4 analyzes the impact of information updating on the decisions of the manufacturer and the retailer and compares contract performances before and after information updating. Section 5 presents the impact of information accuracy on both parties' decisions and profits. Section 6 gives numerical examples to show the decision variation and profit variation under different parameters and the impact of information accuracy on the value of information updating. Section 7 concludes this paper and presents directions for future research. Proofs are presented in the appendixes.

\section{Literature}

This paper investigates supply chain contracting under bilateral information updating and effects of bilateral information updating. In general, the supply chain contracting literature under information updating can be classified into two categories: demand information updating and supply information updating. Demand information updating has been widely investigated but supply information has not been widely investigated, and we refer readers to Shen et al. [6] for comprehensive reviews. In order to highlight our contributions, we review three aspects of the literature that are particularly relevant to our study.

The first steam is supply chain contracting under demand information updating. The pricing contracts (e.g., wholesale price contract) under demand information updating are widely investigated by many scholars [7-11]. Quantity-related contracts, such as quantity flexibility contracts [12-14] and quantity commitment contracts $[15,16]$ are also addressed under demand information updating. Agreement contracts specifying price $[17,18]$ ) and agreement contracts specifying quantity $[19,20]$ are also investigated under demand information updating. Additionally, some other contracts such as capacity reservation contracts [21], advance purchase contracts [21, 22], and dual purchase contracts [7] are addressed. Ozer and Wei [21] study an advance purchase contract. They show that the advance purchase contract with an appropriate payback agreement can achieve channel coordination under asymmetric forecast information. Ozer et al. [5] give a dual purchase contract through which the manufacturer provides a discount for orders placed before the forecast update. They show that the dual purchase contract outperforms the wholesale price contract. Chintapalli et al. [22] show that a contract that contains advance-order discount and a 
minimum order quantity requirement coordinates the supply chain under demand forecasting.

The second stream is supply chain contracting under supply information updating. Supply information includes capacity information, yield information, lead time information, and input cost information [23]. For the production cost, the method of learning effect is often used to characterize the production cost variation. The literature assumes the production cost has linear learning effect [24] or stochastic learning effect [25-28]. Thus, production cost reduction is possible. However, some practices show that the production cost may increase or decrease because of some uncertainty, e.g., price change of raw material. Gurnani and Tang [1] consider a setting where purchasing cost increases or decreases with a probability under demand information updating. Following Gurnani and Tang [1], Choi et al. [29] consider a case where the ordering cost at the first stage is known but the ordering cost at the second stage is uncertain. In [30], the unit delivery cost (and hence the product cost) is formulated as a decreasing function of the lead time. In contrast, in [31], a newsvendor can place multiple orders with increasing ordering cost over time. More practically, our work considers the setting where production cost can increase or decrease. We then use the Bayesian approach to characterize the production cost updating and explain the ordering cost variation via production cost uncertainty.

Compared with the literature on demand information updating or supply information updating, our work has the following differences. First, we consider bilateral information updating. Specifically, the supplier updates the production cost according to the price of raw material, and the retailer can update demand information. Second, we investigate both parties' optimal decisions under bilateral information updating, that is, the supplier gives an adjusted wholesale price and the retailer makes an adjusted order quantity. Most literature focuses on the retailer's optimal order under demand information updating [1,29-31] or the optimal wholesale price $[7,21,32]$ under demand information updating. There are also some papers investigating the supply chain parties' decision, e.g., the optimal order policy, under the supply information updating [2]. Our work considers the optimal decisions under demand information updating and production cost updating. Ozer and Wei [21] and Ozer et al. [7] show that under symmetric forecast information, a low advance wholesale price (purchase cost) induces the retailer to place a large order before the forecast update and a small order after forecast update. Our work investigates the impact of market outlook. Different from the results in Ozer and Wei [21] and Ozer et al. [7], we show that the optimal wholesale price and the optimal order quantity after information updating are relevant to the market outlook. The retailer places an additional order even if the wholesale price rises when the market outlook is good, but places an order with the minimum order quantity even if the wholesale price falls when the market outlook is bad. Gurnani and Tang [1] study the order decision of a retailer who faces uncertain purchase cost (wholesale price) after demand information is updated. We extend their setting by varying the wholesale price based on production cost updating. We show how the wholesale price varies in different conditions, which depends on bilateral information updating and how the retailer makes his strategic order decisions. Third, the contracts in this work combine the idea of advance purchase contracts, minimum commitment contracts, and wholesale price contracts. The contracts provide two different transfer payments according to the wholesale price variation based on bilateral information updating. The contracts are flexible and complemented easily.

Our work also shows the effects of information accuracy on the supply chain, supplier, and retailer (or buyer) profits. On the demand side, Taylor [32], Taylor and Xiao [33], Miyaoka and Hausman [34], and Amornpetchkul et al. [35] show that more accurate forecasts are not always profitable to the supplier and the retailer. Their work shows that the effect of demand information accuracy on supply chain parties' profit is dependent on contract structure and the capability of demand forecasting. To the best of our knowledge, the impact of the accuracy of production cost has not been investigated. Our work focuses on the effect of the accuracy of the production cost and market demand as well as the effect of market variation on supply chain parties' profits. We show that with a good market outlook, low production cost, high information accuracy of production cost, or high information accuracy of market demand is beneficial to the manufacturer, the retailer, and the supply chain. On the contrary, with a bad market outlook, high production cost, high information accuracy of production cost, or high information accuracy of market demand is harmful to the manufacturer, the retailer, and the supply chain. Our results complement the existing literature on the effects of information accuracy on the supply chain from the perspective of market variation.

\section{Model Assumption}

In this section, we outline how information is updated and the sequence of events.

3.1. Information Structure. Consider a risk-neutral manufacturer (she) selling a single new product to a risk-neutral retailer (he) who faces the following inverse demand curve $p=a+\theta-q$, where the retail price $p$ is jointly determined by the clearing price $a$, market condition $\theta$, and the retailer's order quantity $q$. In this expression, $\theta$ is a continuous random variable distributed in $(l, u)(l$ and $u$ are real numbers and $l<u$ ) with a mean of $\widetilde{\theta}$, a variance of $\sigma_{\theta}^{2}$, and $a+l>0$. This demand curve is common in the literature of economics [36] and operations management [10, 37-39].

Before new production begins, the manufacturer only has an estimation of the production cost based on a similar product. Specifically, the production cost $c \in[\underline{c}, \bar{c}]$ has a mean of $\widetilde{c}$ and variance $\sigma_{c}^{2}$ which is common knowledge for the manufacturer and the retailer. Besides, the retailer is able to make a more accurate demand forecast by obtaining demand signal $y$ (e.g., consumers' preference), which is an unbiased estimator of $\theta$. Also, the manufacturer can update 
his production cost by acquiring a signal $x$ from the raw material market, which is an unbiased estimator of $c$. We assume a linear-expectation information structure: the posterior expectation of the market condition $E(\theta \mid y)$ is a linear function of the signal $y$ and the posterior expectation of the production cost $E(c \mid x)$ is a linear function of the signal $x$ (these assumptions are commonly used in the literature $[33,38-42])$. This information structure includes well-known conjugate pairs such as normal-normal, beta-binomial, and gamma-Poisson. Moreover, $E(\theta \mid y)$ is a weighted average of $\widetilde{\theta}$ and signal $y[38,42,43]$, $E(\theta \mid y)=\widetilde{\theta}\left(1+t_{\theta} \sigma_{\theta}^{2}\right)+t_{\theta} \sigma_{\theta}^{2} y /\left(1+t_{\theta} \sigma_{\theta}^{2}\right)$, where $t_{\theta}=1 / E$ $(\operatorname{var}(y \mid \theta)) \equiv 1 / v_{\theta}^{2}$. Also, $E(c \mid x)$ is a weighted average of $\widetilde{c}$ and signal $x$ [43], $E(c \mid x)=\widetilde{c}\left(1+t_{c} \sigma_{c}^{2}\right)+t_{c} \sigma_{c}^{2} x /\left(1+t_{c} \sigma_{c}^{2}\right)$, where $t_{c}=1 / E(\operatorname{var}(x \mid c)) \equiv 1 / v_{c}^{2}$.

3.2. Sequence of Events. In order to make appropriate decisions based on updated information, the manufacturer and the retailer firstly make agreements on the initial wholesale price $w_{0}$, the minimum order quantity $q_{0}$ (to reserve the manufacturer's capacity), and demand information sharing. Besides, they agree on decisions adjustment and total transfer payment $T$ based on bilateral information updating. Secondly, the manufacturer learns the signal $x$ and estimates her production cost as $E(c \mid x)$. At the same time, the retailer obtains signal $y$ and estimates the market demand as $E(\theta \mid y)$ and shares it with the manufacturer. Because the retailer has a lower ability of forecasting the market, he has to ask for order quantity adjustment after demand updating. It is necessary for the retailer to share the updated demand information with the manufacturer. Thirdly, the manufacturer offers a wholesale price $w_{1}$ based on the updated production cost and the updated demand information. Since the updated production cost can be inferred from the wholesale price, the manufacturer does not need to share it with the retailer. Given the adjusted wholesale price $w_{1}$, the retailer places an additional order of $\left(q_{1}-q_{0}\right)^{+}$units, where $q_{1}$ is the total amount of products sold at a retail price $p$. The timeline is shown in Figure 1.

Here is one example in practice in accordance with such a sequence of events. In the flu vaccine industry, supply is highly uncertain because of the biological nature of vaccine production. For example, in the United States, there was an oversupply of 18.4 million doses in the 2006$2007 \mathrm{flu}$ season, whereas there was an undersupply of nearly 50 million doses in the 2004-2005 flu season due to contamination at the Chiron's plant (Health Industry Distributors Association 2007). At the same time, vaccine demand is also highly uncertain because it is primarily determined by the prevalence and severity of the unpredictable flu activities [4]. The manufacturer combines both advance and regular selling strategies. Because of the long production lead time of six to eight months, the advance orders of flu vaccines are placed long before the actual flu season. Thus, these advance order quantities have no information value. When the actual supply information and demand information are realized, the manufacturer and the retailer update the wholesale price and order quantity.
The regular wholesale price of flu vaccines tends to be higher (or lower) than the average when the actual demand is higher (or lower) than the actual supply. For example, the regular wholesale price can be substantially high during the shortage period; e.g., $\$ 7$ per dose as compared with $\$ 3$ per dose for the advance order during the 2000 2001 season (United States General Accounting Office, 2001) [5].

3.3. Initial Decisions. In this section, we discuss the initial wholesale price and the order quantity before information updating. We formulate the interactions between the manufacturer and the retailer as a Stackelberg game under which the manufacturer is the leader and the retailer is the follower.

Given any wholesale price $w_{0}$ set by the manufacturer, the retailer determines his order quantity $q_{0}$ to maximize his profit $\prod_{r}=\left(p-w_{0}\right) q_{0}=\left(a+\tilde{\theta}-q_{0}-w_{0}\right) q_{0}$. The manufacturer determines $w_{0}$ to maximize her profit $\prod_{m}=w_{0} q_{0}-\widetilde{c} q_{0}$. Thus, the optimal wholesale price is $w_{0}^{*}=$ $(a+\widetilde{\theta}+\widetilde{c}) / 2$ and consequently the optimal order quantity is $q_{0}^{*}=(a+\widetilde{\theta}-\widetilde{c}) / 4$. These decisions may be adjusted after the information is updated. If the updated information is the same as previously expected, the manufacturer and the retailer adopt the initial decisions as their final decisions. In the next section, we will discuss the decisions adjustment.

\section{Decisions and Profits under Information Updating}

After the signals about production cost and market demand are obtained, the manufacturer changes her wholesale price and the retailer orders additional order quantity. Since the minimum order quantity is committed, the final order is not less than the initial order quantity $q_{0}$. Consequently, the transfer payment made by the retailer to the manufacturer can be expressed as $T=w_{1 i} q_{1 i}-\left(w_{1 i}-w_{0}\right)^{+} q_{0}, i=1,2$, where $q_{1 i} \geq q_{0}$ and $(x)^{+} \equiv \max (x, 0)$ and $w_{1 i}\left(q_{1 i}\right)$ is the wholesale price (overall order quantity) after information updating. The transfer payment varies according to the wholesale price, that is, $T_{1}=w_{0} q_{0}+w_{11}\left(q_{11}-q_{0}\right)$ if $w_{11}>w_{0}$ and $T_{2}=w_{12} q_{12}$ if $w_{12} \leq w_{0}$. In the first case, the retailer purchases the committed order quantity at the initial wholesale price and the additional order quantity at the new wholesale price. In the second case, the retailer purchases the entire order at the new wholesale price. The transfer payment is equivalent to $T_{2}=$ $w_{0} q_{0}+w_{12}\left(q_{12}-q_{0}\right)+\left(w_{12}-w_{0}\right) q_{0}$.

We next give the profit functions of the manufacturer and the retailer, and then give the optimal wholesale price and order quantity under bilateral information updating.

If the new wholesale price is higher than the initial one, the transfer payment made to the manufacturer is $T_{1}=w_{11}\left(q_{11}-q_{0}^{*}\right)+w_{0} q_{0}^{*}$. The profits of the manufacturer and the retailer are as follows:

$$
\begin{aligned}
& \prod_{h 1}^{11}=T_{1}-\tilde{c} q_{0}-E(c \mid x)\left(q_{11}-q_{0}\right), \\
& \prod_{r}^{h}=p q_{11}-T_{1} .
\end{aligned}
$$




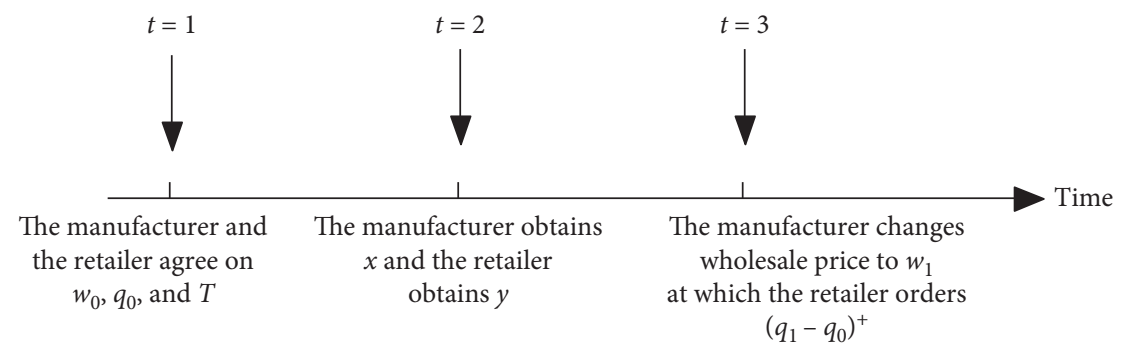

Figure 1: Sequence of events.

If the new wholesale price is not higher than the initial one, the transfer payment made to the manufacturer is $T_{2}=w_{12} q_{12}$. The profits of the manufacturer and the retailer are as follows:

$$
\begin{aligned}
& \prod_{m}^{12}=T_{2}-\tilde{c} q_{0}-E(c \mid x)\left(q_{12}-q_{0}\right), \\
& \prod_{r}^{12}=p q_{12}-T_{2} .
\end{aligned}
$$

We then have the following results.

\section{Lemma 1}

$$
\begin{aligned}
& w_{11}^{*}=\frac{a+E(c \mid x)+E(\theta \mid y)}{2}-q_{0}^{*}, \\
& q_{11}^{*}=\frac{a-E(c \mid x)+E(\theta \mid y)}{4}+\frac{1}{2} q_{0}^{*}, \\
& w_{12}^{*}=\frac{a+E(c \mid x)+E(\theta \mid y)}{2}, \\
& q_{12}^{*}=\frac{a-E(c \mid x)+E(\theta \mid y)}{4} .
\end{aligned}
$$

Lemma 1 shows that if the manufacturer raises the wholesale price after information updating, the optimal wholesale price and the order quantity are related to the committed order quantity. However, if the manufacturer lowers her wholesale price, the optimal wholesale price and the order quantity are irrelevant to the committed order quantity. The rationale behind Lemma 1 is as follows. As the market outlook becomes better or the production cost increases, the manufacturer offers a higher wholesale price to ensure her profit margin. The retailer purchases the minimum order quantity at the initial wholesale price and purchases an additional quantity at an adjusted wholesale price which is higher than the initial wholesale price. Thus, the retailer prefers to order the minimum quantity. In some cases, he orders nothing. Correspondingly, the optimal wholesale price is relevant to the minimum order quantity. As the market outlook becomes worse or the production cost decreases, the manufacturer offers a lower wholesale price. The retailer can purchase all order quantity at an adjusted wholesale price which is lower than the initial wholesale price. Therefore, the retailer will order more than the minimum order quantity, which makes the minimum quantity requirement no longer an issue.

In what conditions will the manufacturer give a higher (lower) or the same wholesale price and the retailer make an additional order? We next answer this question and show how the manufacturer and the retailer should make decisions strategically in different situations.

4.1. Decisions under Information Updating. In this section, we discuss how information updating affects the decisions of the manufacturer and the retailer. Specifically, we give the conditions in which the manufacturer should adjust the wholesale price.

Definition 1. $\beta(y) \equiv E(\theta \mid y)-\tilde{\theta}$.

There are three cases to consider: $\beta(y)=0, \beta(y)>0$, and $\beta(y)<0$, which can reflect the market demand variation. $\beta(y)=0$ means that the posterior expectation of market demand is the same as pre-expectation; $\beta(y)>0(\beta(y)<0)$ means that the posterior expectation of market demand is higher (lower) than previously expected, which represents a good (bad) market outlook. With such a definition, we have Proposition 1.

Proposition 1. Let $\beta(y) \equiv E(\theta \mid y)-\widetilde{\theta}, \alpha \equiv 2 q_{0}^{*}>0$, and we shall have

(1) $E(c \mid x)>\widetilde{c}-\beta(y)+\alpha$ if and only if the wholesale price rises after information updating

(2) $E(c \mid x)<\widetilde{c}-\beta(y)$ if and only if the wholesale price falls after information updating

(3) $\tilde{c}-\beta(y) \leq E(c \mid x) \leq \widetilde{c}-\beta(y)+\alpha$ if and only if the wholesale price remains unchanged after information updating

Proposition 1 shows conditions in which the manufacturer should adjust the wholesale price. We can see that in addition to the market variation, the manufacturer also considers her production cost variation to adjust the wholesale price (see in Figure 2).

(1) If the market outlook is $\operatorname{good}(\beta(y)>0)$, the manufacturer offers a lower wholesale price (compared with the initial setting) only when the updated production cost is very small. The manufacturer keeps his initial wholesale price when the updated production cost is relatively small. This enables the manufacturer to increase her profit margin when the market outlook is good. Surprisingly, when the market is sufficiently $\operatorname{good}(\beta(y)>\alpha)$, the 
manufacturer knows that the retailer is highly likely to order more; thus, she offers a higher wholesale price, even if the updated production cost is lower than expected. The higher wholesale price leads to a higher profit margin for a given updated production cost.

(2) If the market outlook is bad $(\beta(y)<0)$, the manufacturer offers a lower wholesale price (compared with initial setting) even if the updated production cost is larger than expected. The main reason is that facing a bad market outlook, the manufacturer strategically reduces the wholesale price to stimulate the retailer's order. Besides, the manufacturer keeps the initial wholesale price if the production cost falls in the interval $(\tilde{c}-\beta(y), \tilde{c}-\beta(y)+\alpha)$ which is relatively wide. The lower bound $\tilde{c}-\beta(y)$ is larger than the expected production cost $\tilde{c}$. This implies that when the updated production cost is larger than expected, the manufacturer still does not offer an increased wholesale price. When the market outlook is the same as expected $\beta(y)=0$, the manufacturer will not increase the wholesale price. Different from the case of a bad market outlook, the manufacturer will not offer a lower wholesale price than the initial setting when the updated production cost is the same as expected.

Proposition 1 provides the wholesale price strategy and conditions for adjustment when the production cost and the market outlook vary. The main managerial insight is that when the manufacturer offers the wholesale price, she should consider not only the production cost variation but also the market outlook. When the market outlook is not better than expected, offering a lower wholesale price is an appropriate strategy. When the market outlook is better than expected, offering a higher wholesale price is reasonable.

Given the wholesale price set by the manufacturer, the retailer makes his order decisions based on bilateral information updating. We next show the retailer's order strategy as the wholesale price and the market varies (Figures 2(a)-2(c)).

\section{Proposition 2}

(1) When $0<\beta(y)<\bar{c}-\tilde{c}-\alpha$, if $E(c \mid x) \in[\underline{c}, \tilde{c}-\beta(y)]$, $q_{12}^{*} \geq q_{0}^{*}+(\beta(y) / 2) ; \quad$ if $\quad E(c \mid x) \in[\widetilde{c}-\beta(y), \widetilde{c}-$ $\beta(y)+\alpha], \quad q_{12}^{*}=q_{0}^{*}+(\beta(y) / 2) ; \quad$ if $\quad E(c \mid x) \epsilon$ $[\widetilde{c}-\beta(y)+\alpha, \widetilde{c}+\beta(y)+\alpha], \quad q_{0}^{*}+(\beta(y) / 2) \geq q_{11}^{*} \geq$ $q_{0}^{*}$; if $E(c \mid x) \in[\widetilde{c}+\beta(y)+\alpha, \bar{c}], q_{11}^{*}=q_{0}^{*}$

(2) When $\beta(y)>\bar{c}-\widetilde{c}-\alpha$, if $E(c \mid x) \in[\underline{c}, \widetilde{c}-\beta(y)]$, $q_{12}^{*} \geq q_{0}^{*}+(\beta(y) / 2) ; \quad$ if $\quad E(c \mid x) \in[\widetilde{c}-\beta(y), \widetilde{c}-$ $\beta(y)+\alpha], \quad q_{12}^{*}=q_{0}^{*}+(\beta(y) / 2) ; \quad$ if $E(c \mid x) \in[\widetilde{c}+$ $\beta(y)+\alpha, \bar{c}], q_{0}^{*}+(\beta(y) / 2) \geq q_{11}^{*} \geq q_{0}^{*}$

(3) When $\underline{c}-\tilde{c}<\beta(y) \leq 0$, if $E(c \mid x) \in[\underline{c}, \widetilde{c}+\beta(y)]$, $q_{12}^{*} \geq q_{0}^{*}$; if $E(c \mid x) \in[\widetilde{c}+\beta(y), \bar{c}], q_{11}^{*}=q_{12}^{*}=q_{0}^{*}$

Figures 2(a) to 2(c) show the retailer's optimal overall order quantity in three cases of the updated market outlook, i.e., $\quad 0<\beta(y)<\bar{c}-\tilde{c}-\alpha, \quad \beta(y)>\bar{c}-\tilde{c}-\alpha, \quad$ and $\quad \underline{c}-\tilde{c}<$ $\beta(y) \leq 0$. compared with Figure 2, Figures $3(a)$ to $3(c)$

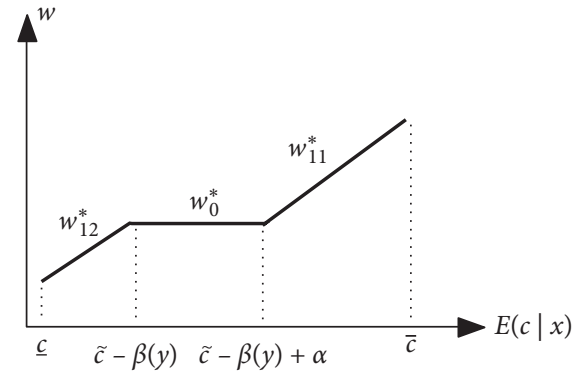

FIGURE 2: Wholesale price variation.

demonstrate some important properties of the order quantity as follows:

(1) When the market outlook is sufficiently good $(\beta(y)>\bar{c}-\tilde{c}-\alpha)$, even if the wholesale price rises, the retailer still places an additional order, which is observed from the line segment CD in Figure 3(a). The rationale behind the curves is as follows. The retailer's order quantity is decreasing with the wholesale price and increasing with the market demand. When the market outlook is sufficiently good, the positive effect of a good market is larger than the negative effect of the increase in the wholesale price. Also, the total order quantity exceeds the minimum quantity.

(2) When the market outlook is relatively good $(0<$ $\beta(y)<\bar{c}-\tilde{c}-\alpha)$, the retailer does not order more than committed if the manufacturer offers a sufficiently high wholesale price $\widetilde{c}+\beta(y)+\alpha<E$ $(c \mid x)<\bar{c}$, which is observed from the line segment $D E$ in Figure 3(b). With a sufficiently high wholesale price, the retailer has to reduce his profit margin. However, when the manufacturer does not offer a sufficiently high wholesale price for $E(c \mid x)<\tilde{c}+\beta(y)+\alpha)$, the retailer does not suffer a loss due to the constraint of the minimum order quantity.

(3) When the market outlook is bad $(\underline{c}-\tilde{c}<\beta(y) \leq 0)$, reducing the wholesale price does not necessarily persuade the retailer to place more orders, which is observed from the line segment BC in Figure 3(c). The decision as to whether or not place an additional order depends on the change in the wholesale price. The retailer is likely to place an additional order only if the wholesale price after information updating goes down. In the case where the wholesale price goes up, the retailer's order quantity is less than his committed minimum order quantity. Since the retailer cannot reduce his committed order, the best decision for the retailer is to keep the order unchanged.

4.2. Value of Information Updating. In this section, we calculate profits for the manufacturer and the retailer before and after information updating. After that, we compare the profits in these two cases to show the value of information updating. 


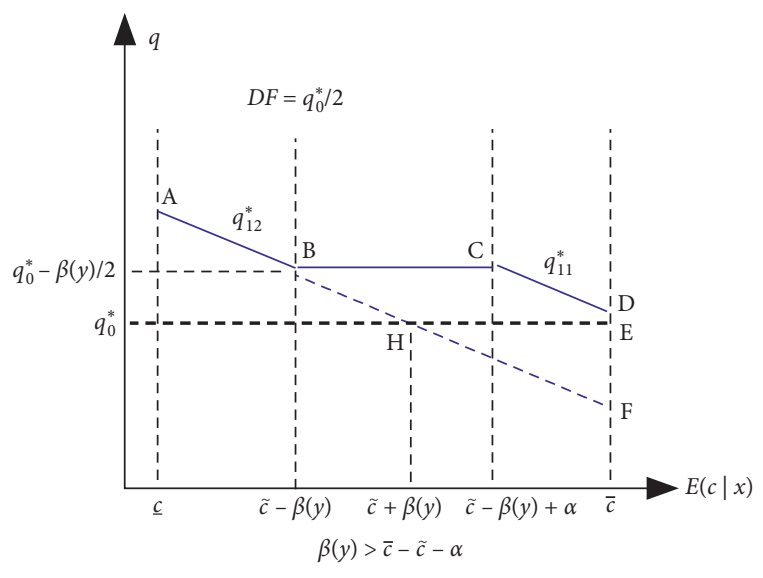

(a)

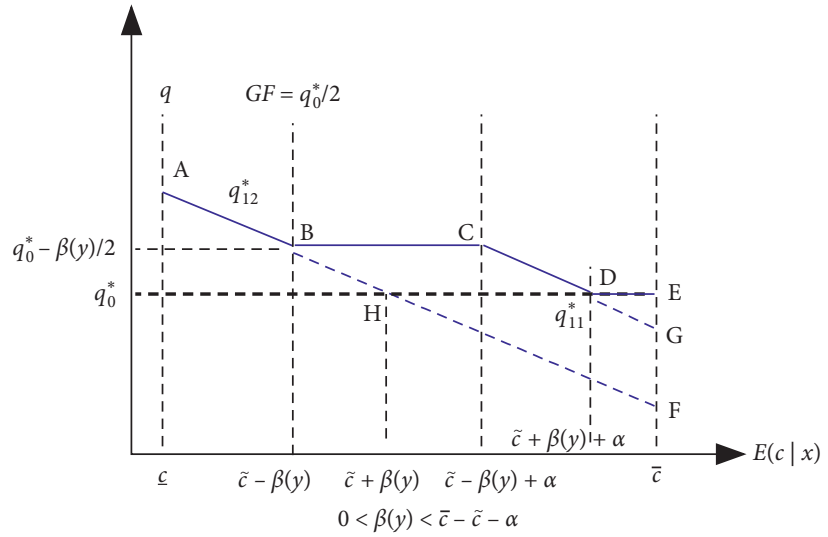

(b)

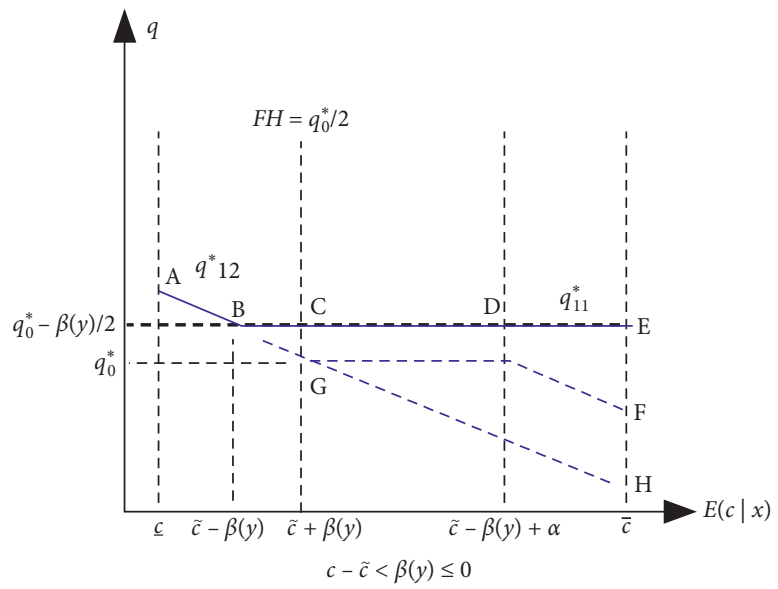

(c)

FIGURE 3: Oder policies.

\section{Proposition 3}

(A) When $w_{11}^{*}>w_{0}^{*}$, $\prod_{m}^{11} \geq \prod_{m}^{0}, \prod_{r}^{11}>\prod_{r}^{0}$, and $\prod_{m}^{11}+$ $\prod_{r}^{11}>\prod_{m}^{0}+\prod_{r}^{0}$

(B) When $w_{12}^{*} \leq w_{0}^{*}, \prod_{r}^{12} \geq \prod_{r}^{0}$ and $\prod_{m}^{12}+\prod_{r}^{12}>\prod_{m}^{0}+$ $\prod_{r}^{0}$ :

If $\beta(y)>0, \prod_{m}^{12} \geq \prod_{m}^{0}$

If $\beta(y)<0$ and $E(c \mid x)<\widetilde{c}+\beta(y)-2 \sqrt{-2 q_{0}^{*} \beta(y)}$, $\prod_{m}^{12}>\prod_{m}^{0}$ holds

If $\beta(y)<0 \quad$ and $\quad \tilde{c}+\beta(y)-2 \sqrt{-2 q_{0}^{*}} \quad \beta(y)<$ $E(c \mid x)<\widetilde{c}+\beta(y)+2 \sqrt{-2 q_{0}^{*} \beta(y)}, \prod_{m}^{12} \leq \prod_{m}^{0}$ holds

Proposition 3 states that wholesale price adjustment and bilateral information updating affect the value of information updating for each supply chain party and the entire supply chain. When the manufacturer faces a high updated production cost $(c>\widetilde{c}-\beta(y)+\alpha)$, she offers a higher wholesale price (compared with the initial wholesale price) (Proposition 1), and in turn, obtains a higher profit margin. Thus, the manufacturer's profit in this case is better than that without information updating.

When the manufacturer faces a relatively smaller updated production cost, she offers a lower wholesale price (compared with the initial wholesale price) (Proposition 1).
The retailer's order quantity is higher than the committed minimum order, that is, the retailer makes his entire order at a lower wholesale price. Thus, the retailer always benefits from information updating. However, the value of information updating for the manufacturer depends on the market demand variation and the production cost variation. When the market outlook is good, the manufacturer always benefits from information updating. The main reason is that the manufacturer's profit margin is increasing with the market variation. With the retailer's larger order quantity (larger than the initial setting), the manufacturer's profit is better than that without information updating. When the market outlook is bad, the manufacturer's profit margin is decreasing with the market variation. Thus, only when the updated production cost is small, $E(c \mid x)<\tilde{c}+\beta(y)-2 \sqrt{-2 q_{0}^{*} \beta(y)}$, the manufacturer benefits from information updating. When the updated production cost is relatively large, $\tilde{c}+\beta(y)-2$ $\sqrt{-2 q_{0}^{*} \beta(y)}<E(c \mid x)<\widetilde{c}+\beta(y)+2 \sqrt{-2 q_{0}^{*} \beta(y)}$, the manufacturer suffers a loss from information updating. Further, when the market outlook becomes worse, the manufacturer suffers more losses. Even if the manufacturer does not always benefit from information updating, the supply chain always benefits from information updating. The main reason is that the value of information updating for the retailer is larger than 
the value of information updating for the manufacturer when the market outlook is bad and the production cost is relatively high.

\section{The Impact of Information Accuracy}

In this section, we present the impact of information accuracy. We firstly show the impact of information accuracy on the decisions and profits and then show the impact of information accuracy on the value of information updating. Based on the analysis, we also give the managerial insight for the supply chain firms.

To show more managerial insights, we consider the case where the market parameter $\theta$ is a normally distributed random variable with mean $\widetilde{\theta}$ and variance $\sigma_{\theta}^{2}$ and the demand signal $y=\theta+\varepsilon_{\theta}$, where $\varepsilon_{\theta}$ is independent of $\theta$ and $\varepsilon_{\theta} \sim N\left(0, v_{\theta}^{2}\right)$. Also, the production cost $c$ is a normally distributed random variable with mean $\widetilde{c}$ and variance $\sigma_{c}^{2}$, and $x=c+\varepsilon_{c}$, where $\varepsilon_{c}$ is independent of $c$ and $\varepsilon_{c} \sim N\left(0, v_{c}^{2}\right)$.

\subsection{Impact of Information Accuracy on Decisions and Profits}

\section{Proposition 4}

(1) When $\beta(y)>0, \partial w_{1 i}^{*} / \partial t_{\theta}>0$ and $\partial q_{1 i}^{*} / \partial t_{\theta}>0$ hold; when $\beta(y) \leq 0, \partial w_{1 i}^{*} / \partial t_{\theta} \leq 0$ and $\partial q_{1 i}^{*} / \partial t_{\theta} \leq 0$ hold

(2) When $\beta(x)>0, \partial w_{1 i}^{*} / \partial t_{c}>0$ and $\partial q_{1 i}^{*} / \partial t_{c}<0$ hold; when $\beta(x) \leq 0, \partial w_{1 i}^{*} / \partial t_{c} \leq 0$ and $\partial q_{1 i}^{*} / \partial t_{c} \geq 0$ hold

Proposition 4 states that market outlook variation, production cost variation, accuracy of production cost, and accuracy of the market demand jointly affect the wholesale price and order quantity. Higher accuracy of market demand means that the retailer knows more about market demand. If the market outlook is good (bad), the retailer prefers to increase (decrease) his order quantity. The manufacturer provides a high wholesale price because the market is volatile. A high wholesale price improves the manufacturer's profit margin. However, if the market outlook is bad, the manufacturer offers a low wholesale price to stimulate the retailer's order so as to reduce her profit loss.

High accuracy of production cost means that the manufacturer knows the production cost well. If the production cost is higher than pre-expectation, the manufacturer increases the wholesale price. Consequently, the retailer lowers his order quantity. If the production cost is lower than preexpectation, the manufacturer decreases the wholesale price. Consequently, the retailer increases his order quantity.

Next, we will show how information accuracy affects the profits of the manufacturer, the retailer, and the supply chain.

\section{Proposition 5}

(1) When $\quad \beta(y)>0, \quad \partial \prod_{m}^{11} / \partial t_{\theta} \geq 0, \quad \partial \prod_{r}^{11} / \partial t_{\theta}>0$, $\partial\left(\prod_{m}^{11}+\prod_{r}^{11}\right) / \partial t_{\theta}>0, \partial \prod_{m}^{12} / \partial t_{\theta}>0, \partial \prod_{r}^{12} / \partial t_{\theta}>0$, and $\partial\left(\prod_{m}^{12}+\prod_{r}^{12}\right) / \partial t_{\theta}>0$

(2) When $\quad \beta(y) \leq 0, \quad \partial \prod_{m}^{11} / \partial t_{\theta} \leq 0, \quad \partial \prod_{r}^{11} / \partial t_{\theta} \leq 0$, $\partial\left(\prod_{m}^{11}+\prod_{r}^{11}\right) / \partial t_{\theta} \leq 0, \quad \partial \prod_{m}^{12} / \partial t_{\theta} \leq 0, \partial \prod_{r}^{12} / \partial t_{\theta} \leq 0$, and $\partial\left(\prod_{m}^{12}+\prod_{r}^{12}\right) / \partial t_{\theta} \leq 0$
Proposition 5 illustrates the impact of the market outlook and the demand information accuracy on profits of the manufacturer, the retailer, and the supply chain. With a good market outlook, high accuracy of market demand leads to a high wholesale price and a large order quantity (Proposition 4). Given a production cost, the profit margin of the manufacturer increases as the market becomes worse. With a larger order quantity, the manufacturer's profit increases with demand accuracy. When the market demand becomes better, the profit margin of the retailer increases. Therefore, the retailer's profit increases with demand accuracy. However, with a bad market outlook, high accuracy of market demand leads to a high wholesale price and a small order quantity (Proposition 4). Given a production cost, the profit margin of the manufacturer decreases as the market becomes worse. With a small order quantity, the manufacturer's profit decreases with the demand accuracy. When the market demand becomes worse, the retailer's profit decreases with demand accuracy.

\section{Proposition 6}

(1) When $\quad \beta(x)>0, \quad \partial \prod_{m}^{11} / \partial t_{c}<0, \quad \partial \prod_{r}^{11} / \partial t_{c} \leq 0$, $\partial\left(\prod_{m}^{11}+\prod_{r}^{11}\right) / \partial t_{c}<0, \partial \prod_{m}^{12} / \partial t_{c}<0, \partial \prod_{r}^{12} / \partial t_{c}<0$, and $\partial\left(\prod_{m}^{12}+\prod_{r}^{12}\right) / \partial t_{c}<0$

(2) When $\quad \beta(x) \leq 0, \quad \partial \prod_{m}^{11} / \partial t_{c} \geq 0, \quad \partial \prod_{r}^{11} / \partial t_{c} \geq 0$, $\partial\left(\prod_{m}^{11}+\prod_{r}^{11}\right) / \partial t_{c} \geq 0 . \partial \prod_{m}^{12} / \partial t_{c} \geq 0, \partial \prod_{r}^{12} / \partial t_{c} \geq 0$, and $\partial\left(\prod_{m}^{12}+\prod_{r}^{12}\right) / \partial t_{c} \geq 0$

Proposition 6 shows the impact of production cost variation and the accuracy of production cost on profits. If the production cost is higher than expected, an accurate production cost enables the manufacturer to increase the wholesale price and the retailer to decrease the order quantity (Proposition 4). The decreased order quantity and the decreased profit margin of the manufacturer result in the manufacturer's profit loss. For the retailer, the decreased order quantity and the decreased profit margin also result in his profit loss. Thus, from the perspective of the system, high accuracy of the production cost cuts the supply chain's profit if the production cost is higher than expected. This implies that there is no need to get more accurate information for the manufacturer when she learned that the production cost is higher than expected. Conversely, if the production cost is lower than expected, an accurate production cost enables the manufacturer to decrease the wholesale price and enables the retailer to increase the order quantity (Proposition 4). Even if the manufacturer sets a low wholesale price, she gains a high profit margin because of the reduction in production cost. Together with the increased order quantity, the manufacturer benefits from knowing accurately about the production cost. Correspondingly, the retailer gains a high profit margin and places a big order, which contributes to the retailer's profit increase as the accuracy of the production cost increases. Hence, from the perspective of the system, high accuracy of the production cost also improves the supply chain's profit if the production cost is lower than expected. One important finding is that the impact of production cost accuracy on the profits of supply chain parties, and the supply chain is not affected by the market outlook. 
Propositions 5 and 6 give a new managerial insight that the impact of market outlook, production cost variation, and information accuracy jointly affect the supply chain profits. Facing a good market outlook and low production cost, high information accuracy of production cost or high information accuracy of market demand is beneficial for the manufacturer, retailer, and supply chain. On the contrary, when facing a bad market outlook and high production cost, high information accuracy of production cost or high information accuracy of market demand is harmful to the manufacturer, the retailer, and the supply chain.

5.2. Impact of Information Accuracy on the Value of Information Updating. In this section, we investigate the impact of information accuracy on the value of information updating. We firstly investigate the impact of demand information accuracy when the market status varies and then investigate the impact of information accuracy of the production cost when the production cost varies.

\section{Proposition 7}

(1) When $\beta(y)>0, \partial\left(\prod_{m}^{11}-\prod_{m}^{0}\right) / \partial t_{\theta} \geq 0, \partial\left(\prod_{r}^{11}-\prod_{r}^{0}\right) /$ $\partial t_{\theta}>0, \partial\left(\prod_{m}^{11}+\prod_{r}^{11}-\left(\prod_{m}^{0}+\prod_{r}^{0}\right)\right) / \partial t_{\theta}>0, \partial\left(\prod_{m}^{12}-\right.$ $\left.\prod_{m}^{0}\right) / \partial t_{\theta}>0, \quad \partial\left(\prod_{r}^{12}-\prod_{r}^{0}\right) / \partial t_{\theta}>0$, and $\partial\left(\prod_{m}^{12}+\right.$ $\left.\prod_{r}^{12}-\left(\prod_{m}^{0}+\prod_{r}^{0}\right)\right) / \partial t_{\theta}>0$

(2) When $\beta(y) \leq 0, \partial\left(\prod_{m}^{11}-\prod_{m}^{0}\right) / \partial t_{\theta} \leq 0, \partial\left(\prod_{r}^{11}-\prod_{r}^{0}\right) /$ $\partial t_{\theta} \leq 0, \partial\left(\prod_{m}^{11}+\prod_{r}^{11}-\left(\prod_{m}^{0}+\prod_{r}^{0}\right)\right) / \partial t_{\theta} \leq 0, \partial\left(\prod_{m}^{12}-\right.$ $\left.\prod_{m}^{0}\right) / \partial t_{\theta} \leq 0, \partial\left(\prod_{r}^{12}-\prod_{r}^{0}\right) / \partial t_{\theta} \leq 0, \quad$ and $\partial\left(\prod_{m}^{12}+\right.$ $\left.\prod_{r}^{12}-\left(\prod_{m}^{0}+\prod_{r}^{0}\right)\right) / \partial t_{\theta} \leq 0$

Proposition 7 illustrates that with a good market outlook, high accuracy of market demand leads to a high value of demand updating. The reason is that high accuracy of market demand increases the profits of the supply chain parties and supply chain (Proposition 5), and the profits of supply chain parties and supply chain are not affected by the information accuracy before information updating. However, with a bad market outlook, high accuracy of market demand is associated with the low value of demand updating. The reason is that high accuracy of market demand decreases the profits of the supply chain parties and supply chain (Proposition 5), and the profits of supply chain parties and supply chain are not affected by the information accuracy before information updating. Therefore, the main managerial insights are as follows. The manufacturer should not always prefer a high demand accuracy, especially when the market outlook is bad. Also, the retailer does not necessarily improve his demand accuracy when the market outlook is bad. However, when the market outlook is good, both the manufacturer and the retailer prefer high accuracy of market demand to ensure their high profitability.

\section{Proposition 8}

(1) When $\beta(x)>0, \partial\left(\prod_{m}^{11}-\prod_{m}^{0}\right) / \partial t_{c}<0, \partial\left(\prod_{r}^{11}-\prod_{r}^{0}\right) /$ $\partial t_{c}<0, \partial\left(\prod_{m}^{11}+\prod_{r}^{11}-\left(\prod_{m}^{0}+\prod_{r}^{0}\right)\right) / \partial t_{c}<0, \partial\left(\prod_{m}^{12}-\right.$ $\left.\prod_{m}^{0}\right) / \partial t_{c}<0, \partial\left(\prod_{r}^{12}-\prod_{r}^{0}\right) / \partial t_{c}<0, \quad$ and $\partial\left(\prod_{m}^{12}+\right.$ $\left.\prod_{r}^{12}-\left(\prod_{m}^{0}+\prod_{r}^{0}\right)\right) / \partial t_{c}<0$
(2) When $\beta(x) \leq 0, \partial\left(\prod_{m}^{11}-\prod_{m}^{0}\right) / \partial t_{c} \geq 0, \partial\left(\prod_{r}^{11}-\prod_{r}^{0}\right) /$ $\partial t_{c} \geq 0, \partial\left(\prod_{m}^{11}+\prod_{r}^{11}-\left(\prod_{m}^{0}+\prod_{r}^{0}\right)\right) / \partial t_{c} \geq 0, \partial\left(\prod_{m}^{12}-\right.$ $\left.\prod_{m}^{0}\right) / \partial t_{c} \geq 0, \partial\left(\prod_{r}^{12}-\prod_{r}^{0}\right) / \partial t_{c} \geq 0$, and $\partial\left(\prod_{m}^{12}+\right.$ $\left.\prod_{r}^{12}-\left(\prod_{m}^{0}+\prod_{r}^{0}\right)\right) / \partial t_{c} \geq 0$

Proposition 8 shows that when the production cost is higher than expected, high accuracy of production cost leads to low value of information updating. The rationale behind Proposition 8 is as follows. High accuracy of production cost increases the wholesale price and decreases the order quantity (Proposition 4).

Since the increase rate of the wholesale price equals the increase rate of the production cost, the manufacturer has an unchanged profit margin. Due to the decreased order quantity, the manufacturer suffers from high accuracy of production cost. Besides, the profit without information updating of the manufacturer is not relevant to the accuracy of production cost. Thus, the value of production cost updating for the manufacturer is decreasing with the information accuracy. In a similar way, with an unchanged profit margin and decreased order quantity, the retailer also suffers profit decrease as the accuracy of production cost increases. Proposition 8 also shows that when the production cost is lower than expected, high accuracy of production cost leads to a high value of information updating. The reason is that a high accuracy of production cost decreases wholesale price and increases the order quantity (Proposition 4). Since the decrease rate of the wholesale price equals the decrease rate of the production cost, the manufacturer has an unchanged profit margin. Due to the increased order quantity, the manufacturer benefits from high accuracy of production cost. Since the decrease rate of the wholesale price equals the decrease rate of the retail price, the retailer has an unchanged profit margin. Due to the increased order quantity, the retailer benefits from high accuracy of production cost. Thus, from the perspective of the supply chain, the value of production cost updating increases as the accuracy of the production cost increase. Propositions 8 provides a managerial insight for the manufacturer and the retailer. The manufacturer and the retailer should not always prefer a high accuracy of production cost, especially when the production cost is larger than expected. However, when the production cost is smaller than expected, both the manufacturer and the retailer prefer high accuracy of production cost to ensure their high profitability.

\section{Numerical Examples}

In this section, we illustrate the information accuracy impact on the expected profit of the manufacturer, the retailer, and the supply chain under various scenarios. We fix $a=10, \widetilde{\theta}=$ 2 , and $\widetilde{c}=2$ and vary the other three parameters: $\eta_{c}=\{-3$, $-2.8,-2.6, \ldots, 3\}, \eta_{\theta}=\{-3,-2.8,-2.6, \ldots, 3\}$, and $t_{c}=$ $\{0, \ldots, 5\}, t_{\theta}=\{0, \ldots, 4\}$. We can compute $w_{0}=7, q_{0}=$ 2.5, $\Pi_{m}^{0}=5$, and $\Pi_{r}^{0}=6.25$. We next compare the wholesale prices, the order quantities, the manufacturer's profits, and the retailer's profits before and after information updating.

6.1. Impact of Information Accuracy on Decisions and Profits. We firstly consider the cases $\beta(x)>0$ and $\beta(y)>0$, i.e., $\eta_{c}>0$ and $\eta_{\theta}>0$. Given $\sigma_{c}=3$ and $\sigma_{\theta}=3$, Figures 4-7 show the 


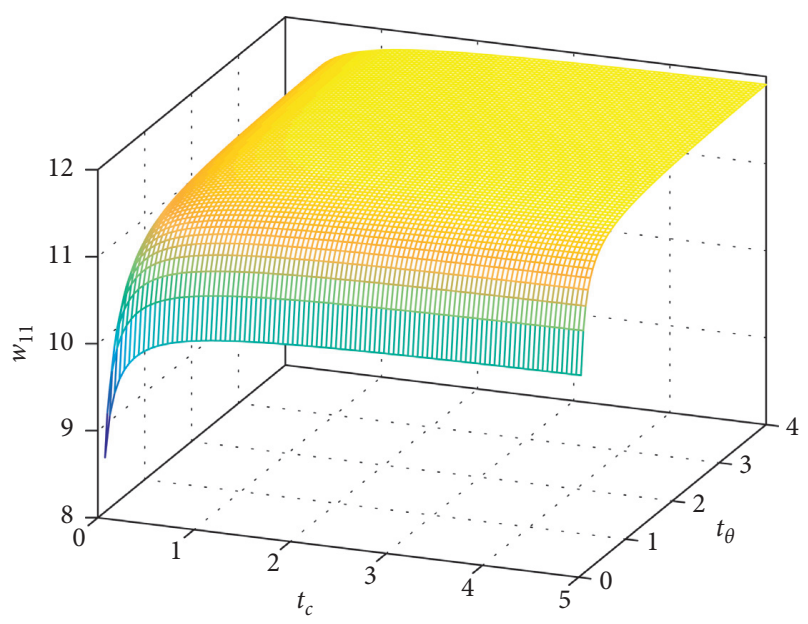

FIgURE 4: Wholesale price $\eta_{c}=2.5$ and $\eta_{\theta}=2.5$.

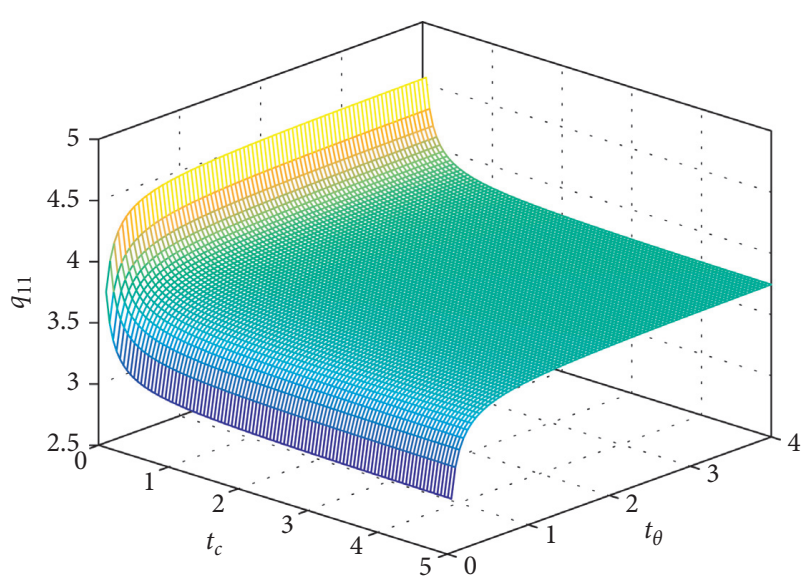

FiguRE 5: Order quantity $\eta_{c}=2.5$ and $\eta_{\theta}=2.5$.

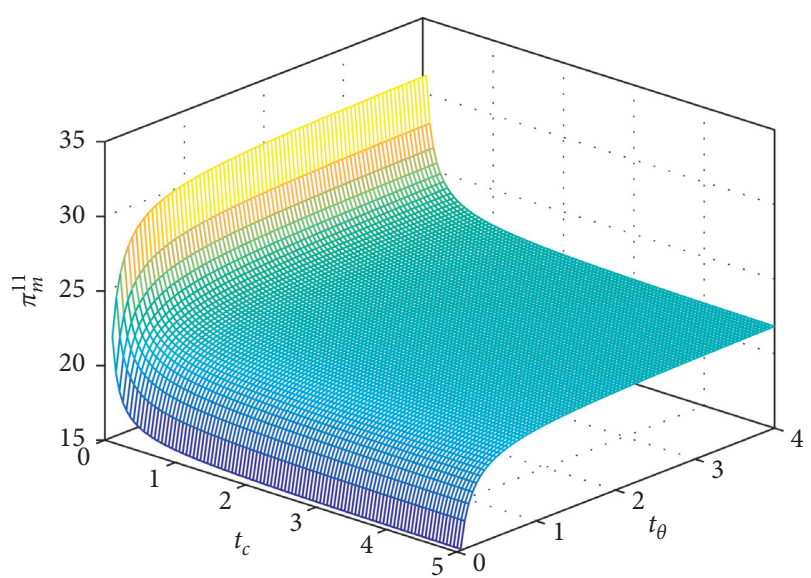

FIGURE 6: Manufacturer's profit $\eta_{c}=2.5$ and $\eta_{\theta}=2.5$.

wholesale price, order quantity, and the manufacturer's profit as well as the retailer's profit when the information accuracy varies for $\eta_{c}=2.5$ and $\eta_{\theta}=2.5$. We have additional observations to Propositions 5 and 6.

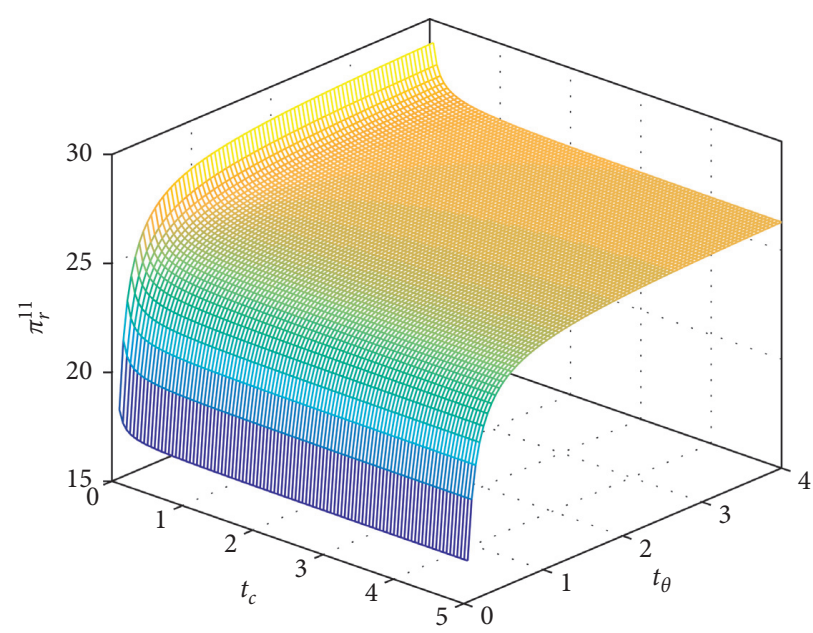

Figure 7: Retailer's profit $\eta_{c}=2.5$ and $\eta_{\theta}=2.5$.

From Figures 4 and 5, we have the following observations:

(1) The wholesale price is higher than the initial wholesale price and the order quantity is higher than the initial order quantity. The manufacturer's profit and the retailer's profit are larger than those before information updating. This means that with better market demand, the manufacturer raises the wholesale price and the retailer raises his order quantity. With a high profit margin, the manufacturer benefits from information updating, even if his production cost rises. Conversely, with a low profit margin, the positive effect of increasing order quantity enables the retailer to benefit from information updating.

(2) The wholesale price increases sharply with the accuracy of production cost and the accuracy of the market demand when the accuracy is relatively low and increases slowly, and with the accuracy of production cost and the accuracy of the market demand when the accuracy is relatively high. This implies that much more accurate production cost and demand does not help the manufacturer adjust her wholesale price when the market outlook is good.

(3) The order quantity increases sharply and then slowly with the accuracy of the market demand but decreases sharply and then slowly with the accuracy of production cost. This implies that the retailer increases his order quantity when he knows more about the market demand, and the retailer decreases his order when he faces a high wholesale price. However, sufficiently high accuracy of the production cost and the market demand do not necessarily affect the retailer's order.

From Figures 6 and 7, we can see that the profits of the manufacturer and the retailer after information updating are larger than that before information updating. More theoretical results can be seen in Proposition 6. The 
manufacture's profit increases sharply and then slowly with the information accuracy of the market demand but decreases sharply and then slowly with the information accuracy of production cost. The retailer's profit increases sharply and then slowly with the information accuracy of the market demand but decreases sharply and then slowly with the information accuracy of production cost. The main reason is as follows. When the production cost increases and the market becomes better, the negative effect of production cost increasing is smaller than the positive effect of market demand becoming better. Knowing more about the market demand when the market becomes better will improve the manufacturer and the retailer's profits.

We next consider the cases $\beta(x)<0$ and $\beta(y)<0$, i.e., $\eta_{c}<0$ and $\eta_{\theta}<0$. Given $\sigma_{c}=3$ and $\sigma_{\theta}=2$, Figures 8-10 show the wholesale price, order quantity, and the manufacturer's profit as well as the retailer's profit when the information accuracy varies for $\eta_{c}=-2.5$ and $\eta_{\theta}=-2.5$.

From Figures 8 and 9, we have the following observations:

(1) The wholesale price is higher than the initial wholesale price and the order quantity is higher than the initial order quantity. The retailer's profit is larger than that before information updating but the manufacturer's profit may be smaller than that before information updating. This contrasts the results when the market is better than expected. The intuition behind is that with worse market demand, the manufacturer reduces the wholesale price, and the retailer raises his order quantity. With a lower marginal profit, the manufacturer may not benefit from information updating, and with a lower marginal profit, the positive effect of increasing order quantity enables the retailer to benefit from information updating.

(2) The wholesale price decreases sharply and then slowly with the information accuracy of production cost and the information accuracy of the market demand. This implies that sufficiently accurate production cost and market demand do not necessarily affect the manufacturer's wholesale price adjustment when the market demand is worse than expected.

(3) The order quantity decreases sharply and then slowly with the information accuracy of the market demand and increases sharply and then slowly with the information accuracy of production cost. This implies that the retailer increases his order quantity when he knows more about the market demand, but sufficiently accurate production cost and market demand do not affect obviously the retailer's order adjustment when the market demand is worse than expected.

From Figures 10 and 11, we can see that, the manufacturer's profit after information updating may be smaller than that before information updating. This happens when the information accuracy of market demand is relatively

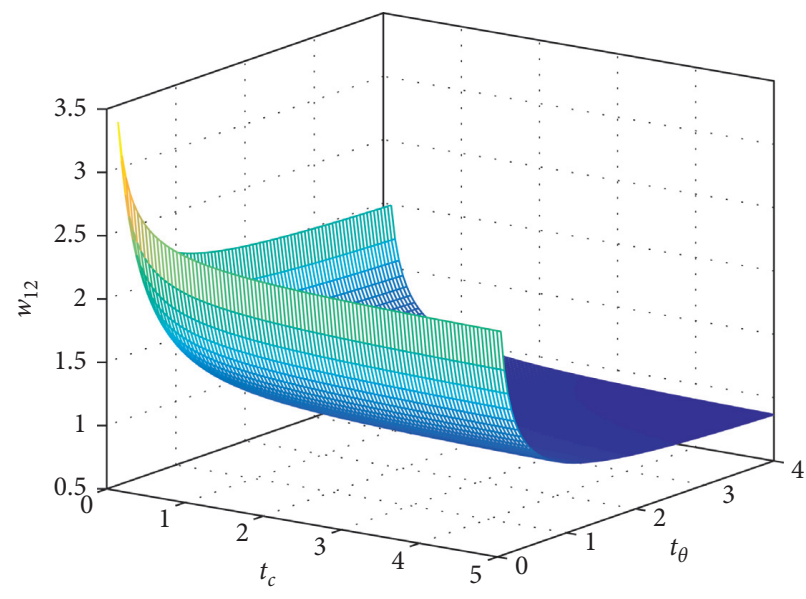

Figure 8: Wholesale price $\eta_{c}=-2.5$ and $\eta_{\theta}=-2.5$.

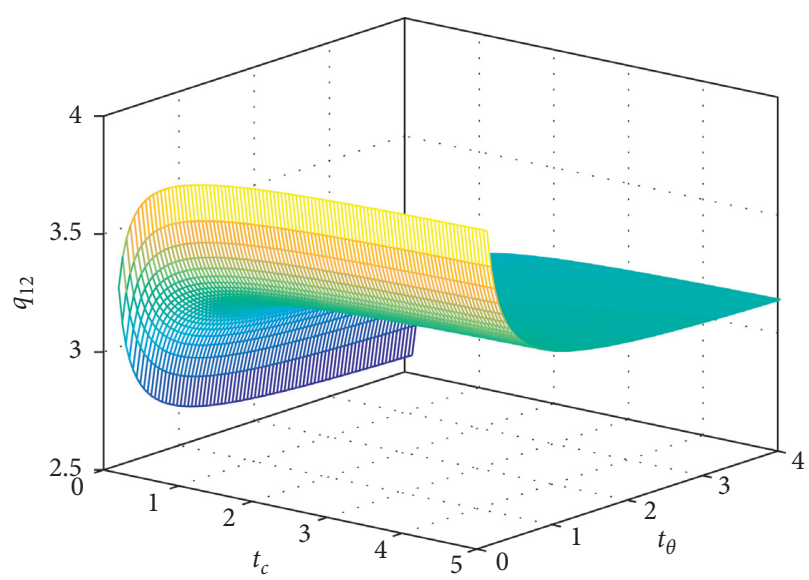

FIGURE 9: Order quantity $\eta_{c}=-2.5$ and $\eta_{\theta}=-2.5$.

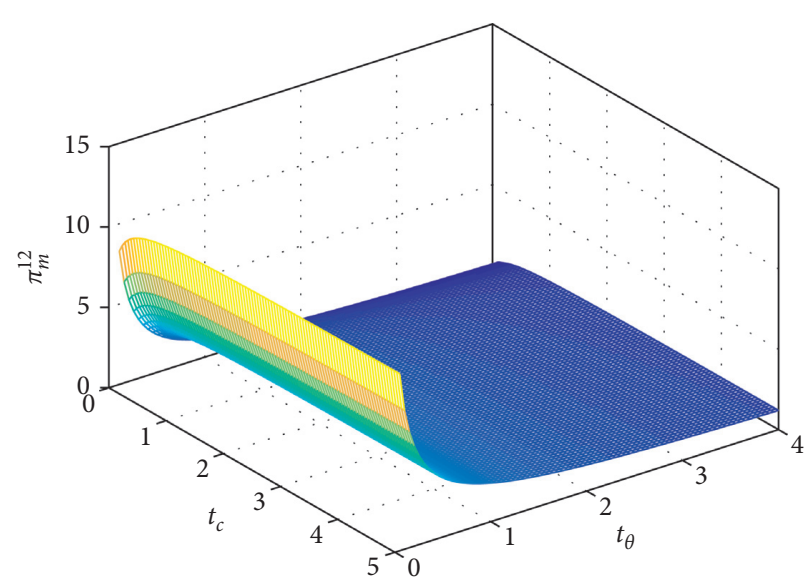

Figure 10: Manufacturer's profit $\eta_{c}=-2.5$ and $\eta_{\theta}=-2.5$.

high. The retailer's profit after information updating is larger than that before information updating. More theoretical results can be seen in Proposition 6. 


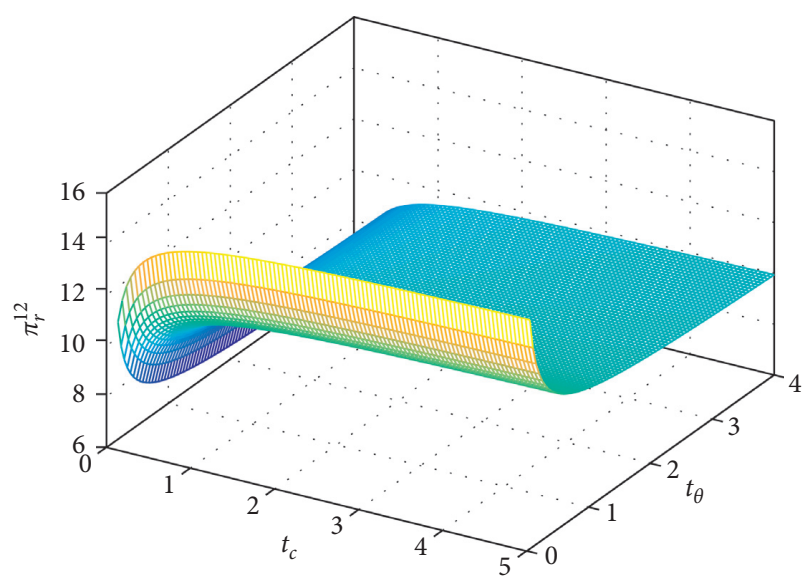

FIgURE 11: Retailer's profit $\eta_{c}=-2.5$ and $\eta_{\theta}=-2.5$.

The manufacture's profit and the retailer's profit are decreasing with the information accuracy of the market demand but increases with the information accuracy of production cost. Also, when the information accuracy of market demand increases, both the manufacturer and the retailer achieve relatively high profits. The main reason is as follows. When the production cost is reduced and the market becomes better, the effect of production cost reduction is larger than the effect of market demand becoming worse. When the market becomes worse, knowing more about the market demand will reduce the manufacturer's and the retailer's profits.

6.2. Impact of Information Accuracy on the Value of Information Updating. Figures 12 and 13 show the value of information updating for the manufacturer and the retailer when the market outlook is good and the production cost is larger than expected. As we can see from Figure 12, the value of information updating for the manufacturer is increasing with the accuracy of demand forecast and decreasing with the accuracy of production cost. This is consistent with theoretical results in Propositions 7 and 8. Moreover, the value of information updating for the manufacturer is always positive. The main reason is that when the market outlook is good, the manufacturer can adjust the wholesale price to his own interests. Also, the value of information updating for the retailer is increasing with the accuracy of demand forecast and decreasing with the accuracy of production cost. This is because when the market outlook is good, the retailer always benefits from information updating no matter whether the wholesale price is higher or lower than the initial setting (Proposition 3).

Figures 14 and 15 show the value of information updating for the manufacturer and the retailer when the market outlook is bad and the production cost is smaller than expected. As we can see from Figure 14, the value of information updating for the manufacturer is decreasing with the accuracy of demand forecast and increasing with the accuracy of production cost. This is consistent with theoretical results in Propositions 7 and 8.

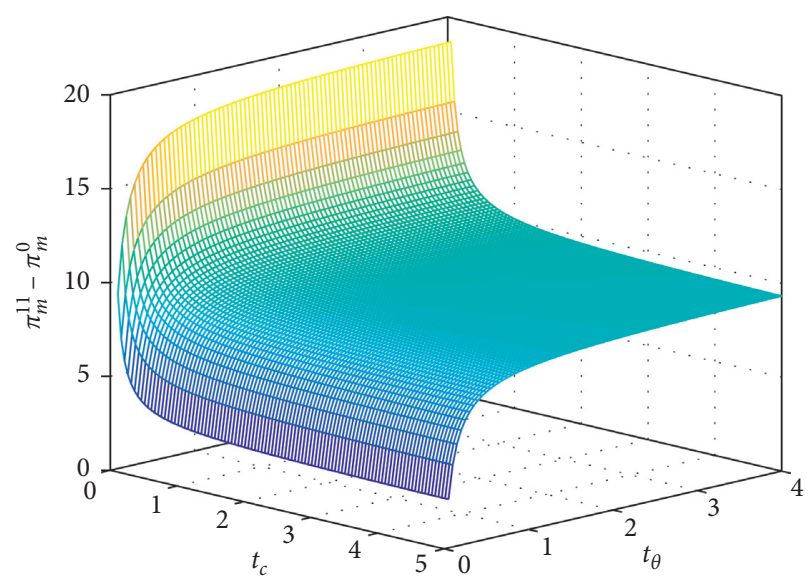

FIgURE 12: Value of information updating for the manufacturer $\eta_{c}=2.5$ and $\eta_{\theta}=2.5$.

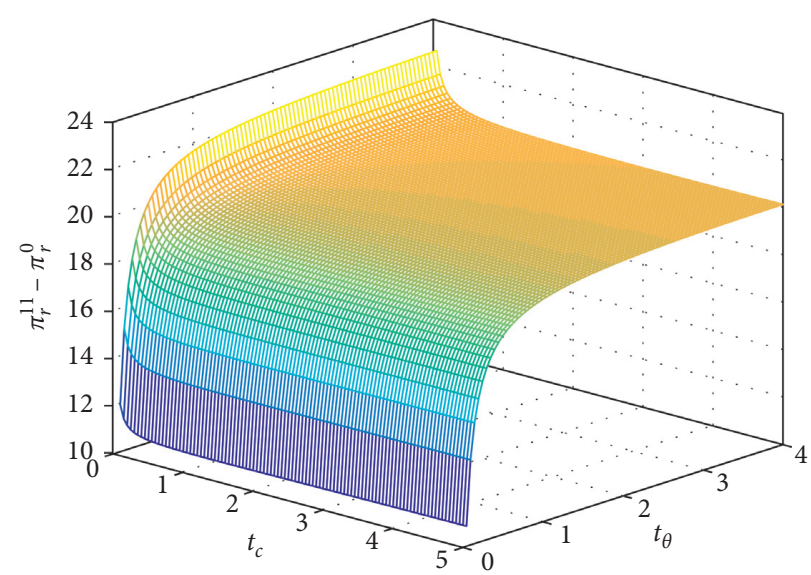

FIGURE 13: Value of information updating for the retailer $\eta_{c}=2.5$ and $\eta_{\theta}=2.5$.

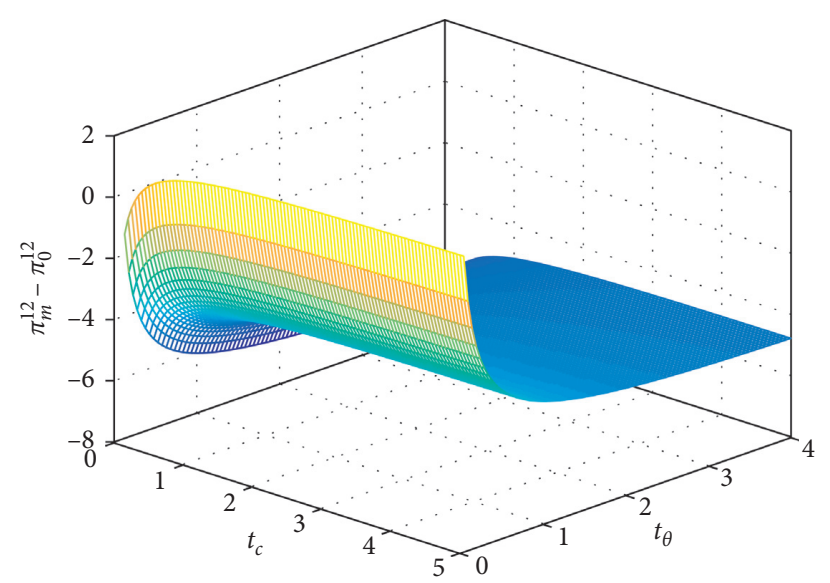

FIGURE 14: Value of information updating for the manufacturer $\eta_{c}=-2.5$ and $\eta_{\theta}=-1.5$.

Moreover, the value of information updating for the manufacturer may not be always positive. The main reason is that when the market outlook is bad, the manufacturer 


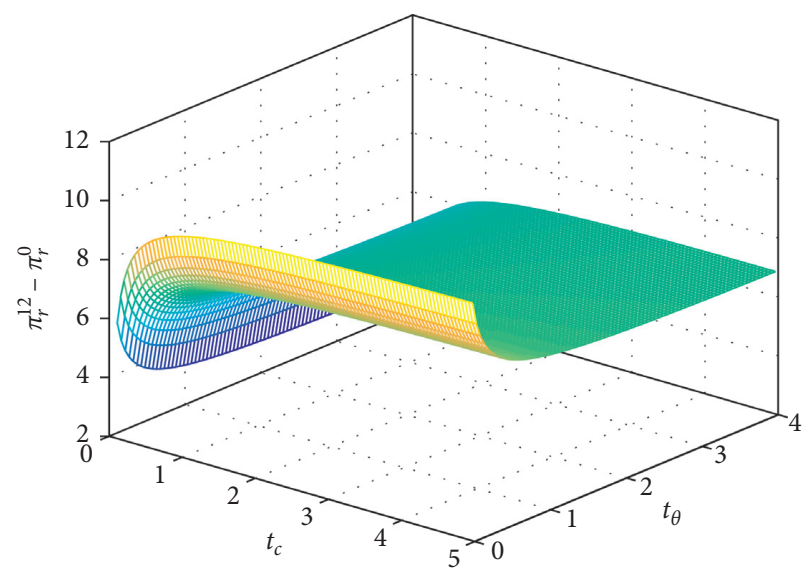

FIGURE 15: Value of information updating for the retailer $\eta_{c}=-2.5$ and $\eta_{\theta}=-1.5$.

benefits from information updating only when the updated production cost is relatively small. When the updated production cost is relatively large, the manufacturer suffers a loss from information updating (Proposition 3). Besides, as the accuracy of market demand increases and the accuracy of production cost decreases, the manufacturer loses more. Also, the value of information updating for the retailer is decreasing with the accuracy of demand forecast and increasing with the accuracy of production cost. But the value of information updating for the retailer is always positive. This is because when the market outlook is bad, the retailer always benefits from information updating no matter if the wholesale price is higher or lower than the initial setting (Proposition 3).

Comparing the value of information updating for the manufacturer and the retailer (Figures 12 vs. 13 and 14 vs. $15)$, we can see that for the manufacturer, the effect of the accuracy of production cost is larger than the effect of the market demand accuracy. However, for the retailer, the effect of the accuracy of production cost is smaller than the effect of the market demand accuracy. The main reason is that the retailer is close to the market and more sensitive to the market variation than the manufacturer. Conversely, the manufacturer is more sensitive to the production cost variation than the retailer.

\section{Conclusions}

In this paper, we investigate the decisions of a manufacturer and a retailer under bilateral information updating. We formulate the interactions between the manufacturer and the retailer as a Stackelberg game. We study a contract that agrees on decisions adjustment and information sharing, which combines the idea of advance purchase contracts and wholesale price contracts.

Some important and interesting observations emerge from this research. First, the production cost variation and market variation jointly affect the wholesale price and order decisions. The manufacturer may not reduce (raise) her wholesale price when the updated production cost is lower (higher) than expected. The retailer places an additional order even if the wholesale price rises when the market outlook is good, but places an order with the minimum order quantity even if the wholesale price falls when the market outlook is bad. Second, the manufacturer may not benefit from information updating. Especially, when the market outlook is bad and production cost is relatively large, the manufacturer suffers a loss from information updating. However, the retailer and the supply chain always benefit from information updating. Third, information accuracy largely affects the profits of the supply chain parties and the supply chain and the value of information updating for the supply chain parties. The manufacturer, the retailer, and the supply chain obtain more profit as the accuracy of production cost increases (decreases) if the market outlook is better (worse) than expected. The manufacturer, the retailer, and the supply chain's profits are increasing (decreasing) with the accuracy of production cost if the updated production cost is higher (lower) than expected. Finally, numerical examples show that when the market demand is better (worse) than expected, the impact of the information accuracy of market demand on the profits of the manufacturer and the retailer is larger (smaller) than the impact of information accuracy of production cost. The abovementioned observations significantly enrich current knowledge about demand forecasting and information updating in supply chains and provide some managerial insights. The retailer should not always seek a high demand accuracy, especially when the market outlook is bad. The manufacturer should not always seek a high accuracy of production cost, especially when the production cost is larger than expected.

Furthermore, research can relax some key assumptions made in this paper. One such assumption is the precommitted agreement of information sharing. If the manufacturer and the retailer do not share information, the bilateral information asymmetry exists between the manufacturer and the retailer. The interactions between the two parties will be much more complex. Another assumption is that the minimum order quantity is given under the Stackelberg game. Furthermore, analysis on the optimal committed order quantity can be launched in future research.

\section{Data Availability}

The data used to support the findings of this study are available from the corresponding author upon request.

\section{Disclosure}

All the authors declare that they have no conflict of any competing financial, professional, or personal interests from other parties.

\section{Conflicts of Interest}

The authors declare that they have no conflicts of interest.

\section{Acknowledgments}

This work was supported by the National Natural Science Foundation of China (Grant no. 71501161), Ministry of 
Education, Humanities and Social Science Planning Funds (Grant nos. 15YJC630149 and 16YJC630026), Fundamental Research Funds for the Central University (Grant no. skqy201768), Young teachers Fund for the Central University (Grant no. 2018NQN29), and Science and Technology Development of Sichuan Province of China (Grant nos. 2019JDR0345 and 2019JDR0210).

\section{Supplementary Materials}

Proofs of lemmas and propositions. (Supplementary Materials)

\section{References}

[1] H. Gurnani and C. S. Tang, "Note: optimal ordering decisions with uncertain cost and demand forecast updating," Management Science, vol. 45, no. 10, pp. 1456-1462, 1999.

[2] C. S. Tang and R. Yin, "Responsive pricing under supply uncertainty," European Journal of Operational Research, vol. 182, no. 1, pp. 239-255, 2007.

[3] Ö. Özer and W. Wei, "Strategic commitments for an optimal capacity decision under asymmetric forecast information," Management science, vol. 52, no. 8, pp. 1238-1257, 2006.

[4] D. G. Williams, "The influenza vaccine supply chain: structure, risk, and coordination," Doctoral dissertation, 2016.

[5] S.-H. Cho and C. S. Tang, "Advance selling in a supply chain under uncertain supply and demand," Manufacturing \& Service Operations Management, vol. 15, no. 2, pp. 305-319, 2013.

[6] B. Shen, T. M. Choi, and S. Minner, "A review on supply chain contracting with information considerations: information updating and information asymmetry," International Journal of Production Research, vol. 57, pp. 1-39, 2018.

[7] Ö. Özer, O. Uncu, and W. Wei, "Selling to the "Newsvendor" with a forecast update: analysis of a dual purchase contract," European Journal of Operational Research, vol. 182, no. 3, pp. 1150-1176, 2007.

[8] G. P. Cachon and R. Swinney, "Purchasing, pricing, and quick response in the presence of strategic consumers," Management Science, vol. 55, no. 3, pp. 497-511, 2009.

[9] G. P. Cachon and R. Swinney, "The value of fast fashion: quick response, enhanced design, and strategic consumer behavior," Management Science, vol. 57, no. 4, pp. 778-795, 2011.

[10] H. Shin and T. I. Tunca, "Do firms invest in forecasting efficiently? the effect of competition on demand forecast investments and supply chain coordination," Operations Research, vol. 58, no. 6, pp. 1592-1610, 2010.

[11] T.-M. Choi, "Inventory service target in quick response fashion retail supply chains," Service Science, vol. 8, no. 4, pp. 406-419, 2016.

[12] H. Huang, S. P. Sethi, and H. Yan, "Purchase contract management with demand forecast updates," IIE Transactions, vol. 37, no. 8, pp. 775-785, 2005.

[13] J. Wu, "Quantity flexibility contracts under Bayesian updating," Computers \& Operations Research, vol. 32, no. 5, pp. 1267-1288, 2005.

[14] Y. Shi, X. Guo, and Y. Yu, "Dynamic warehouse size planning with demand forecast and contract flexibility," International Journal of Production Research, vol. 56, no. 3, pp. 1313-1325, 2018.

[15] H.-L. Chan, B. Shen, and Y. Cai, "Quick response strategy with cleaner technology in a supply chain: coordination and win-win situation analysis," International Journal of Production Research, vol. 56, no. 10, pp. 3397-3408, 2018.

[16] T.-M. Choi, "Impacts of retailer's risk averse behaviors on quick response fashion supply chain systems," Annals of Operations Research, vol. 268, no. 1-2, pp. 239-257, 2018.

[17] K. L. Donohue, "Efficient supply contracts for fashion goods with forecast updating and two production modes," Management Science, vol. 46, no. 11, pp. 1397-1411, 2000.

[18] T.-M. Choi and P.-S. Chow, "Mean-variance analysis of quick response program," International Journal of Production Economics, vol. 114, no. 2, pp. 456-475, 2008.

[19] E. J. Durango-Cohen and C. A. Yano, "Supplier commitment and production decisions under a forecast-commitment contract," Management Science, vol. 52, no. 1, pp. 54-67, 2006.

[20] P. S. Chow, T. M. Choi, and T. C. E. Cheng, "Impacts of minimum order quantity on a quick response supply chain," IEEE Transactions on Systems, Man, and Cybernetics-Part A: Systems and Humans, vol. 42, no. 4, pp. 868-879, 2012.

[21] Ö. Özer and W. Wei, "Strategic commitments for an optimal capacity decision under asymmetric forecast information," Management Science, vol. 52, no. 8, pp. 1238-1257, 2006.

[22] P. Chintapalli, S. M. Disney, and C. S. Tang, "Coordinating supply chains via advance-order discounts, minimum order quantities, and delegations," Production and Operations Management, vol. 26, no. 12, pp. 2175-2186, 2017.

[23] L. V. Snyder, Z. Atan, P. Peng, Y. Rong, A. J. Schmitt, and B. Sinsoysal, "OR/MS models for supply chain disruptions: a review,” IIE Transactions, vol. 48, no. 2, pp. 89-109, 2016.

[24] F. Álvarez and E. Cerdá, "Analytical solution for a class of learning by doing models with multiplicative uncertainty," Top, vol. 7, no. 1, pp. 1-23, 1999.

[25] J. B. Mazzola and K. F. McCardle, "A Bayesian approach to managing learning-curve uncertainty," Management Science, vol. 42, no. 5, pp. 680-692, 1996.

[26] T. Li and H. Zhang, "Information sharing in a supply chain with a make-to-stock manufacturer," Omega, vol. 50, pp. 115-125, 2015.

[27] A. Basu, T. Jain, and J. Hazra, "Supplier selection under production learning and process improvements," International Journal of Production Economics, vol. 204, pp. 411-420, 2018.

[28] S. Zhang and J. Zhang, "Contract preference with stochastic cost learning in a two-period supply chain under asymmetric information," International Journal of Production Economics, vol. 196, pp. 226-247, 2018.

[29] T.-M. Choi, D. Li, and H. Yan, "Optimal two-stage ordering policy with Bayesian information updating," Journal of the Operational Research Society, vol. 54, no. 8, pp. 846-859, 2003.

[30] T.-M. Choi, D. Li, and H. Yan, "Optimal single ordering policy with multiple delivery modes and Bayesian information updates," Computers \& Operations Research, vol. 31, no. 12, pp. 1965-1984, 2004.

[31] T. Wang, A. Atasu, and M. Kurtuluş, "A multiordering newsvendor model with dynamic forecast evolution," Manufacturing \& Service Operations Management, vol. 14, no. 3, pp. 472-484, 2012.

[32] T. A. Taylor, "Sale timing in a supply chain: when to sell to the retailer," Manufacturing \& Service Operations Management, vol. 8 , no. 1 , pp. 23-42, 2006.

[33] T. A. Taylor and W. Xiao, "Does a manufacturer benefit from selling to a better-forecasting retailer?," Management Science, vol. 56, no. 9, pp. 1584-1598, 2010.

[34] J. Miyaoka and W. H. Hausman, "How improved forecasts can degrade decentralized supply chains," Manufacturing \& 
Service Operations Management, vol. 10, no. 3, pp. 547-562, 2008.

[35] T. B. Amornpetchkul, I. Duenyas, and Ö. Şahin, "Mechanisms to induce buyer forecasting: do suppliers always benefit from better forecasting?," Production and Operations Management, vol. 24, no. 11, pp. 1724-1749, 2015.

[36] X. Vives, Oligopoly Pricing, The MIT Press, Cambridge, MA, USA, 1999.

[37] L. Li and H. Zhang, "Confidentiality and information sharing in supply chain coordination," Management Science, vol. 54, no. 8, pp. 1467-1481, 2008.

[38] A. Y. Ha, S. Tong, and H. Zhang, "Sharing demand information in competing supply chains with production diseconomies," Management Science, vol. 57, no. 3, pp. 566-581, 2011.

[39] W. Shang, A. Y. Ha, and S. Tong, "Information sharing in a supply chain with a common retailer," Management Science, vol. 62, no. 1, pp. 245-263, 2015.

[40] L. Li, "Information sharing in a supply chain with horizontal competition," Management Science, vol. 48, no. 9, pp. 11961212, 2002.

[41] F. Chen, G. Lai, and W. Xiao, "Provision of incentives for information acquisition: forecast-based contracts vs. menus of linear contracts," Management Science, vol. 62, no. 7, pp. 1899-1914, 2016.

[42] A. Y. Ha, Q. Tian, and S. Tong, "Information sharing in competing supply chains with production cost reduction," Manufacturing \& Service Operations Management, vol. 19, no. 2, pp. 246-262, 2017.

[43] W. A. Ericson, "A note on the posterior mean of a population mean," Journal of the Royal Statistical Society: Series B (Methodological), vol. 31, no. 2, pp. 332-334, 1969. 